\title{
LA POESÍA POSMODERNA Y LA CRÍTICA A LA GLOBALIZACIÓN: HUMBERTO LÓPEZ-CRUZ Y MARICEL MAYOR MARSÁN
}

\author{
Jorge Chen Sham
}

\begin{abstract}
RESUMEN
La crítica de los medios de comunicación y de la globalización encuentran, en la poesía cubana del exilio floridiano, dos casos representativos de su impacto y vigencia en Humberto López-Cruz y Maricel Mayor Marsán. Estamos menos acostumbrados a que se despliegue en la escritura poética los debates que se suscitan en una sociedad posmoderna y, desde esa posición del sujeto poético, que mira también la realidad y nos ofrece su punto de vista sobre ella, analizaremos las ilusiones y las carencias que la computadora, la internet, los teléfonos digitales, etc. irradian en la sociedad consumista y neocapitalista.

Palabras clave: López Cruz-Humberto, Mayor Marsán-Maricel, poesía cubana, posmodernidad y crítica a los medios de comunicación.
\end{abstract}

\begin{abstract}
Criticism of the media and of globalization are the subjects of the poetry of Cuban exiles in Florida: of which two representative cases of its impact and validity are Humberto López-Cruz and Maricel Mayor Marsán. We are little accustomed to the use of poetic writing for the discussions that arise in a postmodern society, and from the view of the poetic subject, which also offers a point of view of reality while looking at the illusions and the shortcomings that the computer, the Internet, and digital phones radiate in the Neocapitalist and consumeristic society.

Key words: López Cruz-Humberto, Mayor Marsan-Maricel, Cuban poetry, Postmodernity and critique of the media.
\end{abstract}

La Posmodernidad política se asocia con esa crítica a la hegemonía del capitalismo y a sus más valiosas adquisiciones por un lado; por otro, teoriza para darle su lugar a todos esos sujetos que han sido marginalizados de sus procesos socio-económicos, al tiempo que cuestiona sus circuitos de bienes simbólicos culturales basados en la centralidad europea y

Dr. Jorge Chen Sham. Profesor de la Escuela de Filología, Lingüística y Literatura. Universidad de Costa Rica Correo electrónico: jorgechsh@yahoo.com

Recepción: 16- 12- 2011

Aceptación: 24- 01- 2012 
en la primacía de la razón instrumental y de su idea del progreso. No quiero hacer una gran disquisición teórico-filosófica sobre esta posición cultural; pero es necesario plantear esta condición posmoderna con Jean-François Lyotard para comprender esa visión escéptica, negativa y, a veces, también demoledora que las agendas políticas que abrazan quienes optan por una estética revolucionaria (1984: 71-77), en abierta y franca oposición contra el capitalismo y los fenómenos de la globalización económico-mundial.

Es ahí en donde las críticas no se han hecho esperar en la ciudad letrada y poética hacia el impacto de los medios de comunicación y sus méritos. En este sentido, estamos más acostumbrados a que sea la narrativa o la dramaturgia las que despunten en estos cuestionamientos de la globalización y de los medios de comunicación, ya que son dos géneros que podrían estar más preocupados por la realidad inmediata y se nutren de ella; su impacto y vigencia radicaría en que son discursos más proclives al análisis y a desplegar, en su seno, los debates que se suscitan en una sociedad; pero hallamos ejemplos en poesía, cuando, desde esa posición del sujeto poético, que mira también la realidad y nos ofrecen su punto de vista sobre ella. Analizaremos dos casos en la poesía cubana más reciente, la que se escribe desde los EE. UU. Los dos ejemplos son sintomáticos de esta posición de la ciudad letrada y de una agenda que se nutre de los espacios académicos, pues tanto Humberto López-Cruz como Maricel Mayor Marsán están relacionados con el medio universitario.

En el caso de Humberto López-Cruz, en su poemario Escorzo de un instante (2001), esta crítica de la realidad tecnológica y cibernética está mediatizada por una constatación nihilista, según ha apuntado Luis Jiménez, que fragiliza al sujeto poético bajo "el instante frágil de la escritura" (2008: 74) y se decanta por una tesitura temporal en la que todo futuro, todo porvenir, es sujeto a una revisión desde el presente. Jiménez insiste en este foco de la temporalidad en López-Cruz, porque para él la posmodernidad literaria recrea el futuro (de la humanidad, del cosmos, del planeta) desde un presente, y yo añadiría, amargo y desolador, para que sea esta circunstancia la que permita desarrollar una autorreflexión del presente. Por ejemplo, veamos el caso sintomático de "Sensación pasajera", en donde entramos rápidamente en lo álgido del asunto:

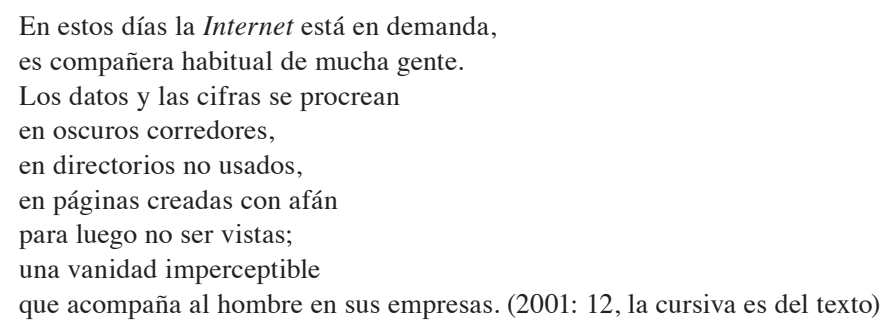

El tono incisivo y acre se despliega en los dos últimos versos desde una actitud que acerca el poema a la sátira, pues apunta hacia un vicio, "la vanidad imperceptible" y cuestiona al ser humano desde esa perspectiva de las "empresas" que acomete, muy propio del discurso de los emblemas morales (y no moralistas) del Renacimiento y del Siglo de Oro que pretende desengañarlo ${ }^{1}$. López-Cruz parte de una constatación del uso acelerado y por lo tanto, necesario en la que la red de Internet ha acaparado nuestra existencia en las sociedades actuales y va apuntando desde el principio del poema ciertas expresiones que van adelantando su toma de posición frente al ciber espacio; por ejemplo, "se procrean/ en oscuros corredores" y "en páginas creadas con afán/ para luego no ser vistas" describen este medio tecnológico en su apariencia, porque todo ocurre, 
no bajo los ojos del ser humano sino en las escondidas ruedas de una información y unos datos que vuelan en las conexiones inalámbricas y satelitales, por eso no son visibles ni perceptibles sus engranajes. Se afirma, entonces, en ese juego entre ser/parecer , que hay algo que se esconde detrás de la red. Y esto no es casual, porque en primer lugar con sorna se señala el fetichismo del objeto:

Es hermoso,

la relación con el objeto toma forma;

ya no es un simple teclado uniforme,

se acaricia,

y las curvas de las teclas se disfrutan. (2001: 12)

Ese poder de seducción se manifiesta para que la red vaya tensando sus hilos sobre el que consume placenteramente la Internet, hasta llegar al enmarañamiento del cual no podemos escapar porque atrapa, crea una necesidad-dependencia para el que se enreda en sus cables y en sus puertas seductoras de links, de conexiones y de páginas-textos. Esos "mundos donde la imaginación descuella", como indica López-Cruz, se transforman en un "laberinto" del cual no hay punto de regreso, es decir, de retorno:

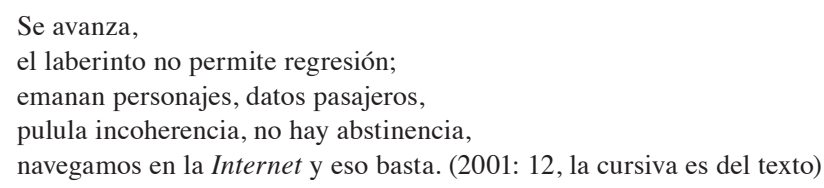

Pero veamos que no se trata de un "laberinto" cualquiera; es uno en el que el verbo seleccionado para ejemplificar la acción realizada por el usuario es sintomático; el verbo "navegar", con el cual se relaciona antonomásticamente la acción de adentrarse en la red, implica en primera instancia un viaje por el mar. Esto desata en nuestro imaginario unas imágenes nada tranquilas, pues el mar ha sido catalogado como un lugar del caos y de incertidumbre para el ser humano; de ahí esa asociación entre el simbolismo del océano y la navegación insegura y sin control que se refleja en el constructo del orbis terrarum (el final de las tierras) que implicaba la idea del universo conocido y cercano (Boruchoff 2001: 856-7), y después del cual no había que aventurarse porque suponía que el ser humano debía controlar su navegación en superficie. Menos aún lo podía hacer en sus profundidades, porque era mejor no caer en ellas, porque era el mundo de lo desconocido y tenebroso (Balavoine 2009: 79-80). Pues bien, este simbolismo de una navegación peligrosa y azarosa en cuanto el ser humano no se sabe medirla, o no se puede controlar sus consecuencias inimaginables, de eso es de lo que se alimenta las imágenes de López-Cruz en su poema:

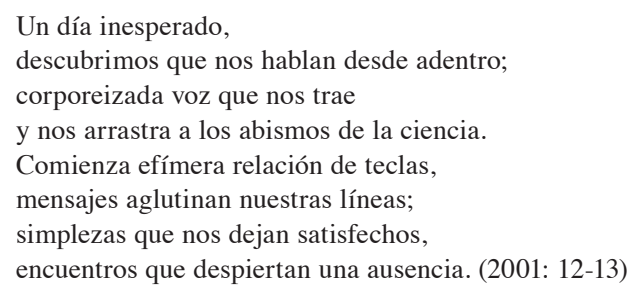

Si nuestra interpretación "acuática" es la pertinente, fíjense ahora en las palabras con las que se describe las sensaciones de caer en esta red; López-Cruz selecciona la metáfora de "los abismos de la ciencia", con el fin de subrayar precisamente las irradiaciones negativas que arrastran al ser humano al borde del precipicio, porque como nos recuerda Claudie Balavoine, las profundidades del mar, es decir, los abismos del mar, representan un desafío y la pérdida de 
toda seguridad (Balavoine 2009: 68) y todo se trastoca en la computadora y dentro de ella en esa relación que, para López-Cruz, es "efímera" y virtual en su sentido más prístino, es decir, que es de "ausencia", como dice el poeta cubano, que no es real sino una ilusión y, para ello, vuelve al campo asociativo de lo marino acuático; veamos lo que es a todas luces una relación sublimada entre el individuo y la computadora:

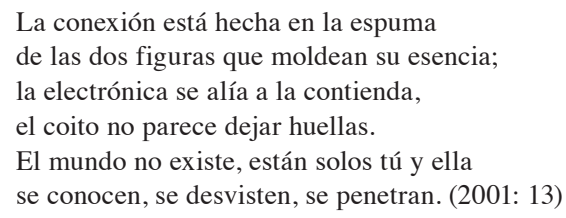

Efectivamente, la seducción de la Internet conduce a una perversión; el objeto se vuelve fetichismo porque el ser humano, fragilizado y así envuelto, ha cambiado los afectos humanos por la relación subliminal con la computadora y con la Internet. Rafael Cabañas Alamán nos recuerda la importancia extrema que, en el ámbito de las perversiones y de la pasión erótica, tiene el fetichismo en cuanto sustitución de la persona amada por la mirada parcializada que se detiene únicamente en el detalle. Esta fragmentación del cuerpo convertido en objeto desemboca en "el problema de la castración" (Cabañas 2002: 27), en la "neurosis obsesiva" (Cabañas 2002: 30), mientras que en López-Cruz, ahora se transmuta el objeto amado y deseado por una máquina. Se ha dejado atrapar en este nuevo laberinto, por el llamado de ese monstruoso (por sus tentáculos e irradiaciones) que representa la Internet. En esta relación de dependencia, él, el internauta, y ella, la red, se juegan la vida perentoriamente en una relación sexualizada. Por ello, insiste LópezCruz en el cierre del poema, en la ilusión que la red promueve creando ilusoriamente una ficción con lo que Luis A. Jiménez ha denominado "la temporalidad del momento y [...] la esencia instantánea de la experiencia" (2008: 77):

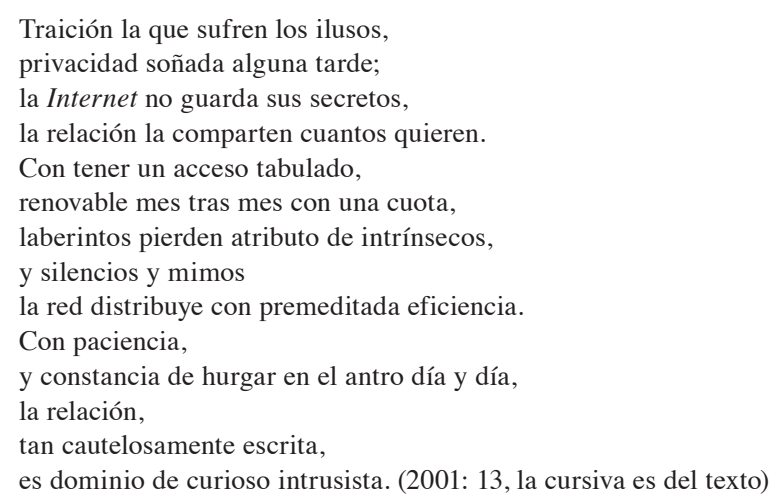

Demoledor e irónico cierre del poema; la relación personal y privada se convierte en una pasión malsana en primer lugar, pues López-Cruz como el poeta satírico desengaña advirtiendo que lo que se esconde debajo de ese fetichismo, de la perversión de una relación personal, es una gran mentira en la que no hay ni "secretos" ni "privacidad". Por eso, a la imagen anterior del internauta que en su computadora privada crea el hilo ficticio de una relación como si fuera un nuevo hilo de Ariadna, que llega a obtener hasta un placer y un goce sexual, López-Cruz ahora desengaña y nos desengaña de la "premeditada eficiencia", calculada y consciente, de la irrealidad del espacio cibernáutico, de sus complacencias efímeras, nada tranquilizadoras cuando compara "la red" con un "antro", en donde como sabemos, se va a disfrutar del sexo y de una relación sexual, 
con una pareja en la que la relación ni es auténtica ni real, por eso se habla de "mes tras mes con una cuota" en tanto transacción regida por lo pecuniario y que está abierta a todo aquel que quiera ser voyeurista, porque "es dominio de curioso intrusista", en evocación a las referencias y códigos utilizados en la Internet para ubicar las direcciones. La difracción de la imagen con que cierra este poema López-Cruz es aplastante en ese cruce de dos planos de la ilusión cibernética; recordemos que califica a los internautas de "ilusos", por lo cual la "privacidad soñada" y el espacio que se crea, la del "antro" como si fuera sexo seguro, adquiere un tono de advertencia contra la pérdida de la intimidad ahora bajo los ojos escrutadores, escondidos, de los que se escudan en la red.

Veamos ahora lo que Maricel Mayor Marsán aporta en Rumores de suburbios (2009), en donde la crítica aguda de la poeta se dirige al estereotipo social del habitante de cualquier suburbio norteamericano de clase media. Demoledora y mordaz se muestra Mayor Marsán en la sección "Suburbios", en la que las buenas maneras y la vida plácida de lo que ella denomina el cuadro de una típica "película de Hollywood" ("Los suburbios", 10) y en donde domina "lo convencional" ("Vecinos de suburbios", 15) le permiten ahondar en la problemática propia del "sueño americano" del consumismo y de las repercusiones que ello tiene en las sociedades posmodernas, sobre todo en la tecnología y los medios de comunicación. Por ejemplo, en el poema "Algunos niños de los suburbios", es implacable ante las repercusiones que este estilo de vida produce en las nuevas generaciones. Tres veces repite unos versos que se constituyen en el estribillo del poema y con el cual comienza y termina el poema: "Algunos niños de los suburbios saben/ todo lo que quieren saber" (29 y 30), en ese juego entre conocimiento y desconocimiento. La ironía surge para constatar efectivamente un doble plano en la afirmación de la voz poética; como en la sátira, está al servicio de una denuncia y desnuda la falsa pretensión de saber todo, ser autosuficientes y pretenciosos en sus conductas y en sus comportamientos, lo cual se hace para ocultar la tremenda podredumbre interior o las existencias vacías. Lo señala Myra M. Medina en la reseña de este poemario de la siguiente manera, como una realidad a la que apunta todo el libro:

\footnotetext{
[...] el suburbio descrito por Mayor Marsán es un análisis de índole social que pone en evidencia lo artificioso de las relaciones interpersonales de sus moradores, la sustitución de lo afectivo por lo material y lo distante de la realidad que viven sus habitantes. Es como si penetrar en el suburbio fuera encapsularse en un mundillo aparte donde los grandes problemas que azotan el mundo [fueran] extraños o inexistentes en la imaginación de quienes allí viven. (Medina 2009-2010: 63)
}

En la tradición hispánica, las sátiras contra las modas, los objetos suntuarios, el boato de la inteligencia tienen una larga trayectoria desde esas diatribas en contra de los falsos eruditos del siglo XVIII, que pululan para criticar la adopción de costumbres extranjeras y cuyos dos rasgos más conspicuos son, a saber, su petulancia y la ostentación pública ${ }^{2}$. En el poema de Mayor Marsán, toda la primera unidad del poema destaca precisamente el boato, el lujo, la pasarela de la moda en la que se convierten las escuelas, un escenario para que se impresione a los compañeros y se haga la ostentación del consumismo:

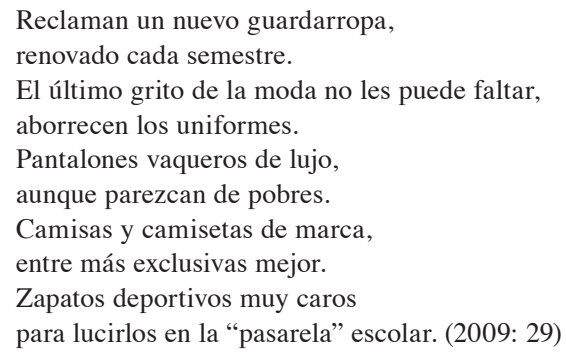


En primer lugar, llama la atención la construcción estrófica del poema en forma de dísticos o pareados. Así, en la primera parte del dístico se anuncia un elemento del "guardarropa", mientras que en la segunda parte se realiza un comentario de tipo irónico que pretende valorar negativamente el uso de la prenda de vestir. Por otra parte, Mayor Marsán comienza el poema con una visión de conjunto, un "nuevo guardarropa", y desfilan "[p]antalones vaqueros de lujo", "[c]amisas y camisetas de marca" y "[z]apatos deportivos muy caros", para culminar con una imagen muy propia de la cultura "fashion" como puede ser la "pasarela". El ojo crítico de la voz poética se inclina por observar los efectos del consumismo que nos hace dependientes y esclavos de lo que no es necesario y es accesorio. Por eso, en la segunda unidad del poema, Mayor Marsán apunta con su dedo incisivo la connivencia en nuestras sociedades posmodernas entre la tecnología y el consumo desaforado:

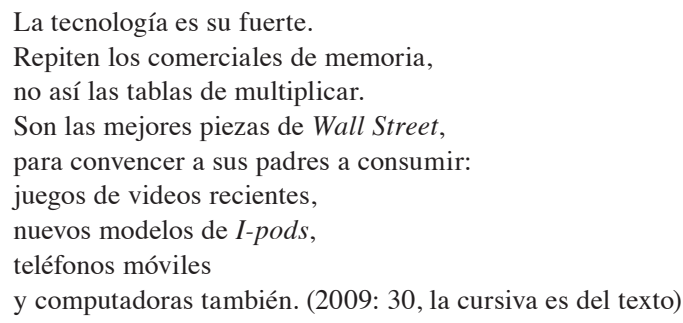

Observemos en primer lugar cómo Mayor Marsán juega con la página para crear una estructura fragmentaria y movible, lo cual motiva el desplazamiento y los hilos que teje lo que ella ve como un rasgo propio de las nuevas generaciones, el consumo de la "tecnología" y no tanto su uso consciente y meticuloso. La prueba es de ello es la contundente afirmación que la voz poética plantea en esa oposición clara del siguiente dístico: "Repiten los comerciales de memoria, / no así las tablas de multiplicar". El abuso de los "comerciales", que está por el todo (el consumo), se pondera con valor negativo sobre "las tablas de multiplicar", aquí también una metonimia de un todo que son las matemáticas, y por extensión el saber. La oposición es entre el consumo de moda versus el conocimiento, para que nos percatemos de que esa pérdida del sentido de la tecnología, la cual debería estar al servicio de la ciencia. Más que aprender cómo funciona y cómo operan estos instrumentos tecnológicos que han transformado nuestro modo de comunicación, "i-pods", "teléfonos móviles" y "computadores" se han convertido en artículos de consumo, en lugar de ser instrumentos al servicio de la ciencia y del mejoramiento de nuestra vida cotidiana; por eso de nuevo se convierte en objetos a los que se les rinde el culto del fetichismo del que veníamos hablando para el caso de López-Cruz. Como la moda del vestir, estamos aquí ahora ante la moda tecnológica, parece apuntar con sorna Maricel Mayor Marsán. Y la pregunta que nos hacemos con ella, son por las causas de esta degeneración, lo cual responde en la tercera y última unidad del poema:

No oses llamarles la atención.

No importa si eres familia, maestro o amigo.

Te reclamarán sus "derechos humanos"

y te amenazarán con repetidas leyes y pseudo-razones

aprendidas, por supuesto, en la televisión.

Tampoco pretendas un espacio en sus vidas,

Están ocupados con Facebook, My Space o You Tube,

con la misma devoción que sus padres se entregan

a sus ocupaciones. (2009: 30, las cursivas son del texto) 
El poema desnuda al sujeto posmoderno en las trampas que la misma tecnología y los dos medios de comunicación de mayor auge como pueden ser la televisión y la Internet producen, en razón de unas libertades civiles y sociales mal comprendidas. Sorprende Mayor Marsán en apuntar hacia el egoísmo, la falta de disciplina y el irrespeto al bien común, porque detrás de esos "derechos humanos" que reclaman sin cesar estos "niños de suburbios" se esconde una cierta miopía de lo que me parece ser la degeneración de nuestro estado de derecho y de nuestra sociedad de consumo, como lo es que no puede haber un derecho sin una obligación, ese contrato social sobre el que se fundaba precisamente nuestra Modernidad Occidental en la versión que la filosofía de la Ilustración promueve ${ }^{3}$. En el poema, estos reclamos o alegaciones tampoco vienen de un estudio concienzudo, meticuloso y serio que venga derivado o promovido de una educación cívica, o de un conocimiento interiorizado, más bien son el producto, como magistralmente apunta la voz poética, de "repetidas leyes y pseudo-razones/ aprendidas, por supuesto, en la televisión", con lo cual se desenmascaran los tentáculos de los mas media, en reproducir sujetos que saben consumir, es decir, que saben repetir sus eslóganes, sus frases hechas, sus clichés ${ }^{4}$; es decir, la ley del consumo priva sobre la reproducción para que el placer se encuentre en la copia y la repetición. Es lo que analiza Jesús Martín-Barbero en "la asimetría de demandas y competencias que se encuentran y negocian en el proceso de comunicación" (2001: 92, la cursiva es del autor) y yo añadiría, en estos procesos de reproducción que radican en la reconocimiento del "objeto mediático" como marca y posición sociales.

Pero por otro lado, Maricel Mayor Marsán, como Humberto López-Cruz también lo hacía, apunta hacia el ensimismamiento y la falta de comunicación en los que los engranajes de la Internet encapsulan a los individuos, pues no hay "espacio en sus vidas" así compartamentalizadas, mientras que tampoco sus padres escapan a las mismas garras del consumismo y de la tecnología, pues la voz poética indica que están en lo suyo; la expresión que utiliza Mayor Marsán es sintomática de esta necesidad de desnudar y de denunciar los efectos de la tecnología, pues subraya que los padres están "con la misma devoción" enfrascados en esa religión que los obliga a adorar, a consumir y a trabajar para repetir ese círculo vicioso que se ha empoderado de los individuos en las sociedades postmodernas. Así las cosas, faltará solamente criticar las garras de los sistemas financieros y descubrir los tentáculos de una economía globalizada y mundial como sucede hoy para completar este panorama desolador que también nos ha obligado a repensar y a desconfiar de los alcances y los valores que fundan el orden mundial, que ha tocado fondo y está en declive; pero habrá que esperar otras voces poéticas que se den esa tarea de dar posicionarse frente a este último capítulo del gran theatrum mundi que López-Cruz y Mayor Marsán ven con la sorna y la eficacia irónica de una tecnología y de unos medios de comunicación que deben permanecer como instrumentos y medios para un fin, y nunca el fin en sí mismos. La poesía posmoderna, escéptica, negativa y sin complejos desnuda de esta manera los alcances de ese consumismo y de ese fetichismo por el objeto y estos dos poetas cubanos nos invitan a mirar con reojo sus "tentáculos" en los medios de comunicación.

\section{Notas}

1. Solamente por recordar esta veta en donde lección moral (y no de "moral") se codea con la función emblemática y simbólica de la existencia humana como trabajo y fatiga, tenemos de Diego Saavedra Fajardo, Ideas de un príncipe cristiano representado en cien empresas (Munich, 1640). Para el discurso moralista áureo las empresas humanas tienen el matiz de ser el producto de la vanidad y de falsas pretensiones; por ello debe desengañarse el ser humano. 
2. Aunque en estas sátiras la adopción de esas nuevas modas se explica en el afán de diferenciarse de lo castizo y español con el fin de aparecer como actual, es necesario insistir en que también estas sátiras denuncian el "barniz" de conocimiento en que caen estos "eruditos", cuyo saber es superficial y encierra sus falsas pretensiones de aparentar ser sabios; véase al respecto mi artículo (Chen 2002).

3. Y me refiero con ello obviamente al contrato social y a la idea que tiene el discurso ilustrado acerca de lo que debe ser el hombre virtuoso y de bien, al servicio de la sociedad y en procura de una felicidad colectiva.

4. ¿Qué interesante esta reflexión de Mayor Marsán!, porque apunta a la misma causa que la sátira del falso o pretencioso erudito, en el siglo XVIII, esgrimía para unos comportamientos deleznables y un saber poco profundo y pastiche (es decir, aprendido porque se repite de otro).

\section{Bibliografía}

Balavoine, Claudie. 2009. "Au-dessous/ au-dessus de la plaine marine: dichotomie symbolique dans l'imaginaire de l'emblématique espagnole (1581-1640)". En: Delpech (Ed.), 65-97.

Bernat-Vistarini, Antonio (Ed.). 2001. Actas del IV Congreso de la Asociación de Cervantistas. Tomo II. Palma de Mallorca: Servei de Publicacions de l'Universitat de les Illes Balears.

Boruchoff, David A. 2001. "Persiles y la poética de la salvación cristiana”. En: Bernat-Vistarini (Ed.), 853-74.

Cabañas Alamán, Rafael. 2002. Fetichismo y perversión en la novela de Ramón Gómez de la Serna. Madrid: Ediciones del Laberinto.

Chen Sham, Jorge. 2002. "La sátira del letrado en la España del S.XVIII: ¿cliché o sociotipo?”. Dieciocho. 25 (2): 229-42.

2010. "La indagación temporal en Escorzo de un instante de Humberto López-Cruz: la búsqueda del instante". Círculo, Revista de Cultura. 40, por aparecer.

Delpech, François (Ed.). 2009. L'imaginaire des espaces acuatiques en Espagne et au Portugal. París: Presses Sorbonne Nouvelle.

Jiménez, Luis A. 2008. "La poesía de Humberto López Cruz en los umbrales del nuevo milenio". Horizontes, Revista de la Pontificia Universidad Católica de Puerto Rico. 50 (98): 73-84.

López-Cruz, Humberto. 2001. Escorzo de un instante. Madrid: Editorial Betania.

Lyotard, Jean-François. 1984. "Answeing the Question, What is Postmodernism?". The Postmodern Condition. Minneapolis: University of Minnesota Press. 
Martín-Barbero, Jesús. 2001. Al sur de la modernidad: Comunicación, globalización y multiculturalidad. Pittsburgh: Instituto Internacional de Literatura Iberoamericana/ University of Pittsburgh.

Mayor Marsán, Maricel. 2009. Rumores de suburbios. Miami: Ediciones Baquiana.

Medina, Myra M. 2009-2010. "Rumores de suburbios de Maricel Mayor Marsán”. Baquiana, Revista Literaria. 11: 62-66. 
